\title{
CHANGES OF BIOLOGICALLY ACTIVE COMPOUND LEVEL IN POTATOES DURING STORAGE UNDER FLUORESCENT LIGHT
}

\author{
Reinis Zarins ${ }^{1 *}$, Zanda Kruma ${ }^{1}$, Ilze Skrabule ${ }^{2}$ \\ $1^{*}$ Department of Food Technology, Faculty of Food Technology, Latvia University of Life Sciences and Technologies, Rigas iela 22, \\ Jelgava, Latvia, e-mail: reinis-zarins@inbox.lv \\ ${ }^{2}$ Institute of Agricultural Resources and Economics, Latvia University of Life Sciences and Technologies, Zinatnes iela 2, \\ Priekuli, Latvia
}

\begin{abstract}
Potatoes (Solanum tuberosum L.) are globally grown and consumed crop and contains many vitally important elements benefiting human diet that makes them actual subject from scientific and food market standpoint. Potatoes naturally contain active element combination named phenolic compounds that are secondary metabolites and enrich potatoes with antioxidant, anticarcinogenic, antibacterial, etc. qualities. The aim of current study was to evaluate changes of biologically active compound level in potatoes during storage under fluorescent light. In present research potatoes of four varieties ('Imanta', 'Magdalena', 'Blue Congo', and 'Lenora') were tested. For the experiment samples were kept under fluorescent light of 1000 lux for 3 and 7 days in climate chamber with controlled temperature of $20{ }^{\circ} \mathrm{C}$ and relative humidity of $40 \%$ that way imitating real shop shelf conditions. Total phenolic content, antioxidant activity (DPPH ${ }^{\circ}$ and ABTS assays), moisture and firmness was determined in potatoes. It was established that during all storage period potato firmness did not change significantly, while moisture decreased in some cases. Phenolic compounds and antioxidant activity showed variety dependent variations.
\end{abstract}

Keywords: potatoes, phenolic compounds, antioxidant activity, storage, fluorescent light

\section{Introduction}

Currently, we are experiencing a growing interest in antioxidant rich products and additives (Huang, 2018). Potato (Solanum tuberosum L.) is in the first line of world's popular crops, and being rich in antioxidants, it is a great addition to the consumer diet (Leo et al., 2008).

One of the most important bioactive compound group is phenolics that are also present in potatoes, showing highly beneficial impact on human health (Velioglu et al., 1998; Espin et al., 2000; Manach et al., 2004). Potatoes are ranged as a third consumed crop in terms of phenolic compound source (Chun et al., 2005).

Numerous studies show that phenolic compounds present antioxidant, antibacterial, anticarcinogenic, anti-inflammatory, antiglycemic, antiviral and vasodilatory features (Mattila, Hellstrom, 2006; Leo et al., 2008; Berghe, 2012; Kazeem et al., 2012; Konaté et al., 2012). Studies also show that human longevity, eyes and mental health as well as cardiovascular system are positively impacted by potato phenolic compounds (Parr, Bolwell, 2000; Manach et al., 2004; Scalbert et al., 2005).

Correlation between potato phenolics and total antioxidant capacity has been established, and that means that higher phenolics level provides higher antioxidant capacity (Andre et al., 2007). Potato analyses show that phenolics can be found in whole tuber, although the skin presents highest phenolics level (Lewis et al., 1999; Nara et al., 2006).

Speaking of variety dependent phenolics level, studies show that all potatoes regardless of variety contain phenolics, but the highest level (almost twice as much) can be found in purple-fleshed (also red-fleshed) varieties in contrast to white-fleshed and yellowfleshed ones (Ezekiel et al., 2013) and it may be explained with high level of anthocyanins that are pigments in such varieties (Im et al., 2008; AlWeshahy, Rao, 2009; Zarins et al., 2018).

Environmental stress is the factor that might force phenolics to accumulate in potatoes tubers and other parts of potato plant as natural protection reaction (Chalker-Scott, 1999; Percival et al., 2000; Sakihama et al., 2000; Grace et al., 2014). Studies presents that artificial light may negatively influence quality of potatoes accelerating formation of glycoalkaloids but also it may have positive effect triggering raise of phenolic compound level and antioxidant activity (Arezki et al., 2001; Izquierdo et al., 2011; Nascimento et al., 2013; Ballester, Lafuente, 2017).

The aim of the current study was to evaluate changes of biologically active compound level in potatoes during storage under fluorescent light.

\section{Materials and Methods}

Raw materials

Potatoes were planted in May and harvested in September 2018. The soil type in the field was sod-podzolic (PVv), sandy loam, $\mathrm{pH} \mathrm{KCl}$ 5.3, organic matter $1.8 \%$, contained $\mathrm{P}_{2} \mathrm{O}_{5} 120 \mathrm{mg} \mathrm{kg}{ }^{-1}, \mathrm{~K}_{2} \mathrm{O}$ $143 \mathrm{mg} \mathrm{kg}^{-1}$. Harvested tubers were kept in the storage facility at air temperature of $4{ }^{\circ} \mathrm{C}$ and relative humidity of $80 \pm 5 \%$. In the experiment, four potato (Solanum tuberosum L.) cultivars with white, yellow and purple coloured flesh were evaluated, namely 'Lenora', 'Imanta', 'Blue Congo', 'Magdalena'. A total of two kilograms of table potato tubers per cultivar were used.

\section{Treatment conditions}

Potatoes were exposed to conditions that are based on mean data obtained from 30 shops during winter period: light -1000 lux, relative air humidity $-40 \%$ and air temperature $-+20{ }^{\circ} \mathrm{C}$. In those conditions, on 
shop shelf, potatoes are stored shortly (during approximately one-week period) before they are purchased by consumer. During all short storage period on the shop shelf, potatoes are exposed to constant light during all working hours of the shop, increased (room) temperature and decreased air humidity. In the current study imitation of real retail shelf conditions were achieved by using climate chamber ICH110 (Memmert GmbH + Co. KG, Germany) with constant and even pre-set humidity and temperature. Luminescent lamp Vagner SDH Circular (32 W) was used as artificial light source.

\section{Firmness measurement}

The changes of potato firmness were determined using TA.HD Plus Texture Analyser (Stable Micro Systems Ltd, United Kingdom) measuring force (Newton) that is needed to penetrate potato skin and flesh. Potato skin and flesh penetration parameters were as follows probe: cylinder, $2 \mathrm{~mm}$ diameter, type $\mathrm{P} / 2$; contact area: $3.00 \mathrm{~mm}^{2}$; test mode: compression; pre-test speed: $1.00 \mathrm{~mm} \mathrm{~s}^{-1}$; test speed: $1.00 \mathrm{~mm} \mathrm{~s}^{-1}$; post-test speed: $10.00 \mathrm{~mm} \mathrm{~s}^{-1}$; distance (penetration depth): $5 \mathrm{~mm}$; trigger type: force; trigger force: $0.049 \mathrm{~N}$.

\section{Chemical analysis}

For extraction of phenolic compounds from potatoes the homogenized potato samples were mixed with ethanol $(80 / 20 \mathrm{v} / \mathrm{v})$ in a conical flask with a magnetic stirrer at room temperature as described in previous experiments (Kampuse et al., 2016). The extraction process was done in triplicate. Determination of total phenolic content (TPC) was done according to the Folin-Ciocalteu spectrophotometric method (Singleton et al., 1999). Antioxidant activity of potato extracts was measured on the basis of scavenging activities of the stable 2,2-diphenyl-1-picrylhydrazyl (DPPH) radical and 2,2'-azino-bis(3-ethylbenzothiazoline-6-sulphonic acid) (ABTS+) radical cation as described in previous experiments (Kampuse et al., 2016).

\section{Statistical analysis}

Experimental results are means of three replications and were analysed by Microsoft Excel 2010 (descriptive statistics) and SPSS 17.00 (ANOVA and correlation analysis). Differences were considered as significant at $\mathrm{p}<0.05$.

\section{Results and Discussion}

\section{Moisture}

In the analysed potato flesh and peels no significant changes in moisture during all storage period were observed, yet a tendency of slight decrease was established (Fig. 1). Measured data presents all potato variety ability to almost retain all moisture in fluorescent lighting storage conditions, although longer exposure to light and longer storage time may show wider variations of moisture changes.

\section{Firmness}

These data allow to understand the changes of potato firmness during storage period. 'Imanta' showed the highest initial (before treatment) firmness of $12.81 \mathrm{~N}$ while 'Blue Congo' and 'Magdalena' presented the lowest amount of force needed $-9.54 \mathrm{~N}$ and $9.66 \mathrm{~N}$, respectively (Fig. 2).

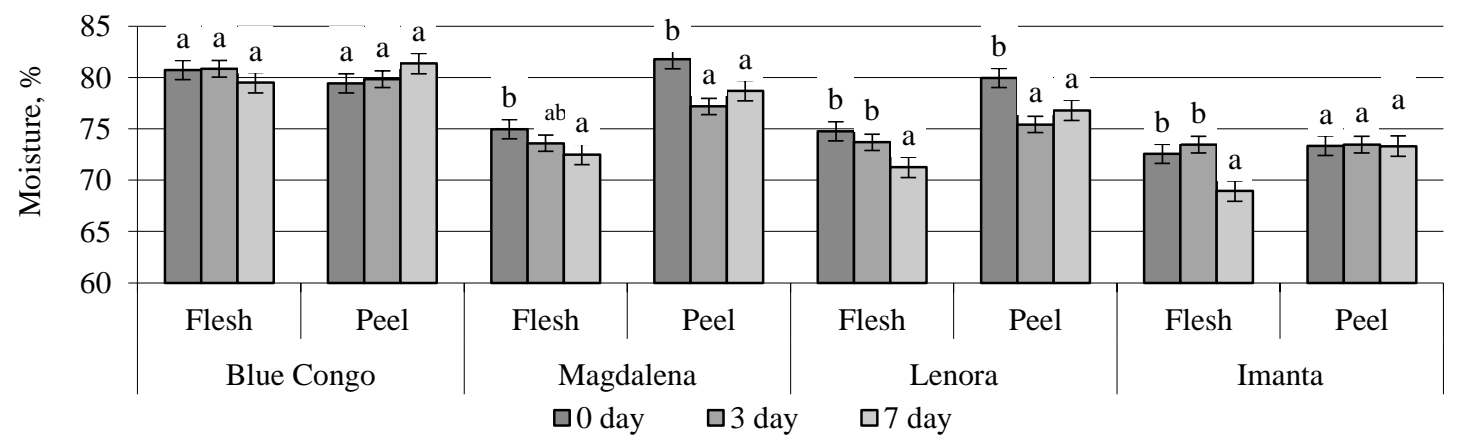

Figure 1. Moisture of potato flesh and peel

The same letters indicate no significant differences between samples $(\mathrm{p}>0.05)$.

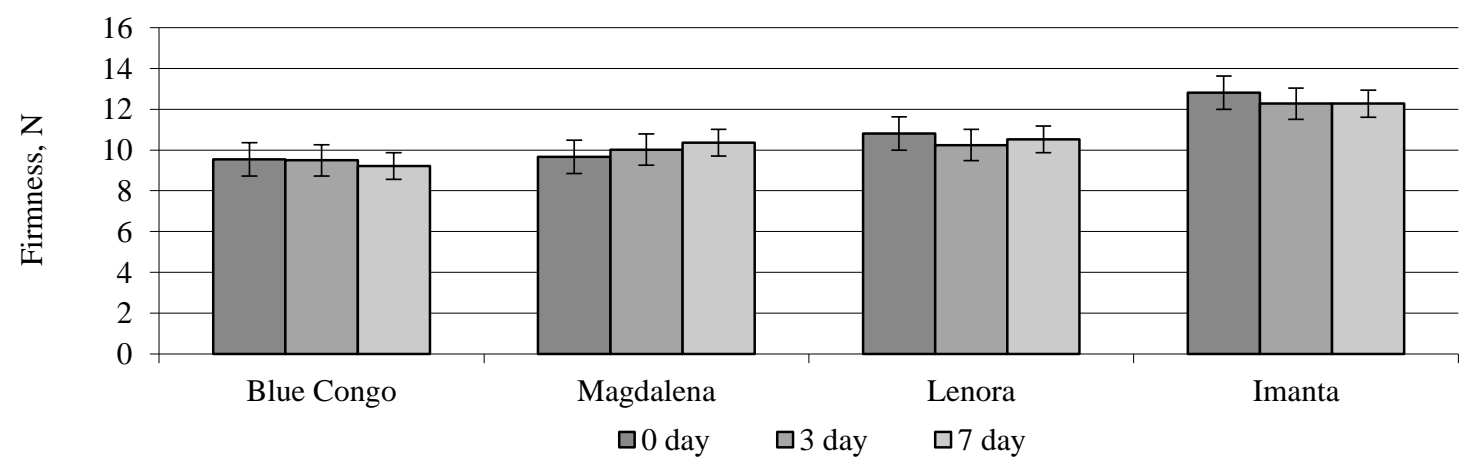

Figure 2. Potato firmness 
Data shows that there was not significant $(\mathrm{p}>0.05)$ variation in firmness during storage, and that allows to conclude that current study conditions for these specific potato varieties did not significantly affect potato firmness. Resource map of potatoes showed that during retail, potato mass losses are only $1.5-3.0 \%$ that also confirms potato stability under shop conditions in terms of moisture and firmness. The most important factors creating losses during storage on shop shelves are caused by potato tuber greening / sprouting (Terry et al., 2011)

\section{Total phenolics}

'Blue Congo' showed the highest initial (before treatment with light) total phenolic content of $265.44 \mathrm{mg} 100 \mathrm{~g}^{-1}$ while 'Imanta' presented the lowest amount of $115.92 \mathrm{mg} 100 \mathrm{~g}^{-1}$ (Fig. 3). 'Magdalena' and 'Lenora' both has no significant differences $(p>0.05)$ in initial total phenolic content of $154.60 \mathrm{mg} 100 \mathrm{~g}^{-1}$ and $154.80 \mathrm{mg} 100 \mathrm{~g}^{-1}$, respectively. After treatment with light, only variety 'Blue Congo' potatoes showed significant decrease of total phenolic content on day 3, while other potato varieties showed increase of total phenolic content. On day 7 all varieties experienced increase of total phenolic content, except 'Imanta' that retained its phenolics content without changes. The highest initial level of total phenolic content in peels was presented by 'Blue Congo' (226.52 mg $100 \mathrm{~g}^{-1}$ ) followed by 'Magdalena' (166.97 mg $\left.100 \mathrm{~g}^{-1}\right)$, 'Lenora' (134.41 mg $100 \mathrm{~g}^{-1}$ ) and 'Imanta' (123.02 mg $100 \mathrm{~g}^{-1}$ ) (Fig. 3). After treatment with light on day 3 all potato varieties showed different tendencies: 'Blue Congo' peels presented increase, 'Magdalena' peels - decrease and for 'Lenora' and 'Imanta' peels no significant differences were observed. After 7 days of treatment, similar tendencies remained. Different studies showed that higher content of phenolics is located in peels (Lewis et al., 1999; Nara et al., 2006), but our results suggest that content is similar and, in some cases, even higher in flesh (varieties 'Blue Congo' and 'Lenora'). Measured data shows that artificial lighting forces variation of total phenolic content making it to increase or decrease depending on variety (Wang et al., 2015). Despite that phenolics changes under artificial lighting are moderate (Sun et al., 2017), longer storage might present more sufficient differences. Other studies showed that under blue light intensive synthesis of phenolic compounds starts from third day (Ballester, Lafuente, 2017).

\section{Antioxidant activity}

It is a natural ability of redox molecules in potatoes to suppress free radicals (Puchau et al., 2010), and studies show that it might be linked to total phenolic content (Leo et al., 2008), however, connection between those two still depends on tested material and conditions.

$D P P H$ scavenging activity: the highest initial 2,2-diphenyl-1-picrylhydrazyl (DPPH) scavenging activity (before treatment with light) was determined in 'Blue Cong', i.e., $14.97 \mathrm{mmol}$ TE $100 \mathrm{~g}^{-1}$ while 'Imanta' presented the lowest activity of $8.44 \mathrm{mmol}$ TE $100 \mathrm{~g}^{-1}$ (Fig. 4).

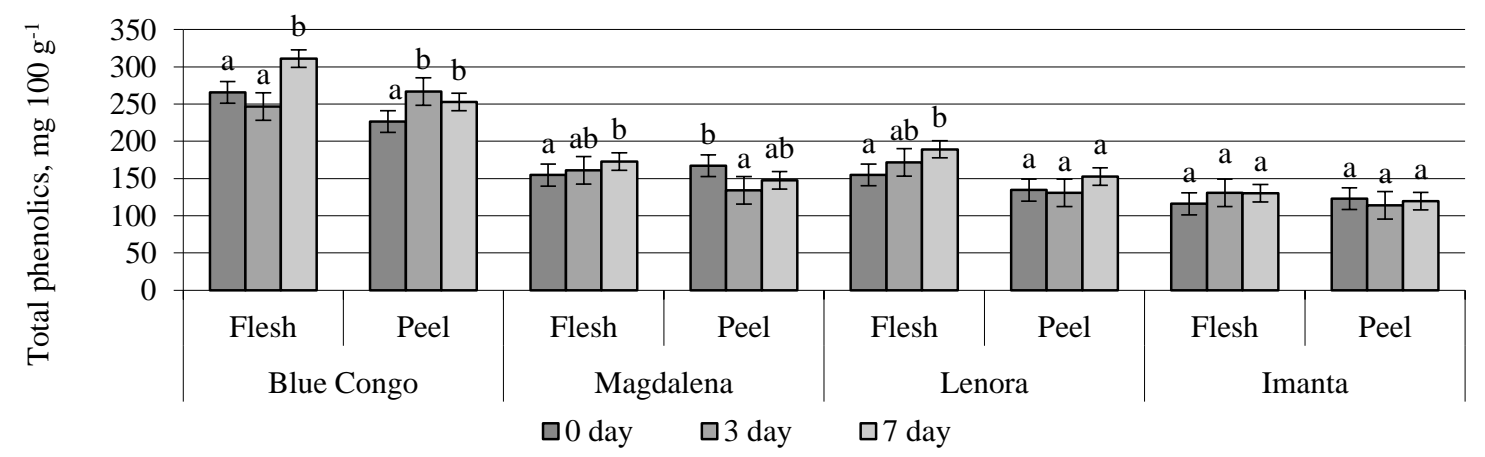

Figure 3. Total phenolic content of potato flesh and peel as the gallic acid equivalent

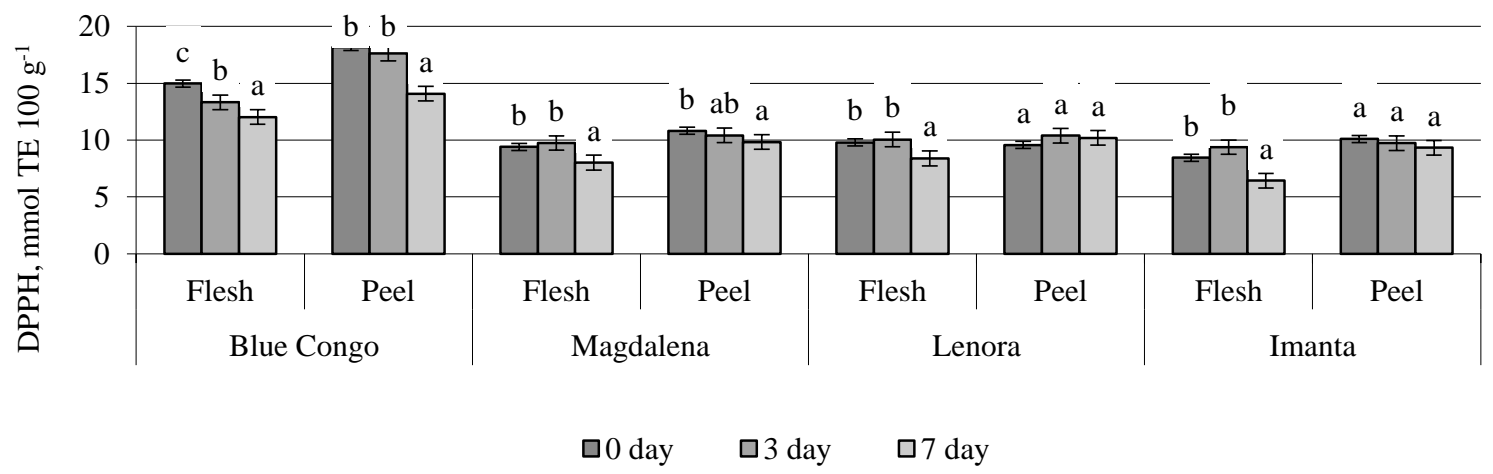

Figure 4. DPPH scavenging activity of potato flesh and peel

The same letters indicate no significant differences between samples $(\mathrm{p}>0.05)$. 


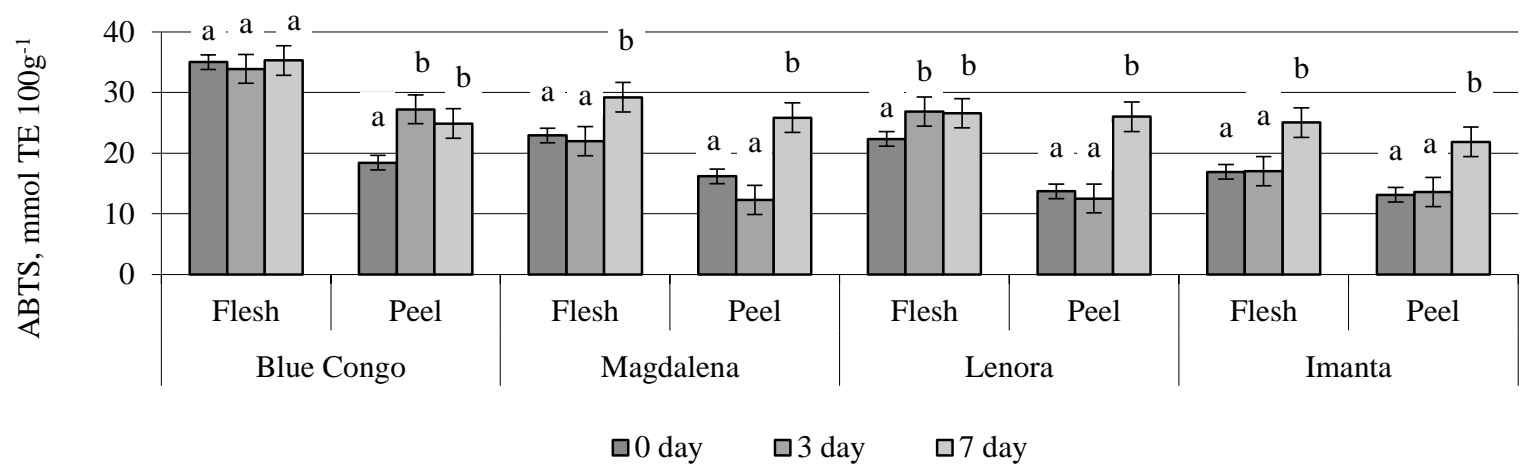

Figure 5. ABTS scavenging activity of potato flesh and peel

The same letters indicate no significant differences between samples ( $p>0.05)$.

'Magdalena' and 'Lenora' both has insignificant differences in initial DPPH scavenging activity of $9.40 \mathrm{mmol}$ TE $100 \mathrm{~g} \mathrm{~g}^{-1}$ and $9.78 \mathrm{mmol}$ TE $100 \mathrm{~g}^{-1}$ respectively. After treatment with light all potato varieties showed insignificant changes in scavenging activity on day 3 , except 'Blue Congo' that presented a decrease. Although day 7 comes with DPPH scavenging activity decrease in all cases compared to day 3, i.e., 'Blue Congo' shows $12.02 \mathrm{mmol} \mathrm{TE} 100 \mathrm{~g}^{-1}$, 'Magdalena' $\quad\left(8.01 \mathrm{mmol} \mathrm{TE} 100 \mathrm{~g} \mathrm{~g}^{-1}\right), \quad$ 'Lenora' $\left(8.38 \mathrm{mmol} \mathrm{TE} 100 \mathrm{~g} \mathrm{~g}^{-1}\right)$ and 'Imanta' (6.42 mmol TE 100 $\left.\mathrm{g}^{-1}\right)$. 'Blue Congo' showed the highest initial DPPH scavenging activity of potato peels presenting $18.18 \mathrm{mmol}$ TE $100 \mathrm{~g}^{-1}$ while 'Lenora' had the lowest activity of 9.37 mmol TE $100 \mathrm{~g}^{-1}$ (Fig. 4) 'Magdalena' and 'Imanta' both has insignificant differences in initial DPPH scavenging activity of $10.80 \mathrm{mmol} \mathrm{TE} 100 \mathrm{~g}^{-1}$ and $10.09 \mathrm{mmol}$ TE $100 \mathrm{~g}^{-1}$ respectively. After 7 days treatment DPPH scavenging activity decreased in all peels compared to day 3, i.e., 'Blue Congo' showed $14.08 \mathrm{mmol}$ TE $100 \mathrm{~g}^{-1}$, 'Magdalena' (9.81 mmol TE $\left.100 \mathrm{~g}^{-1}\right)$, 'Lenora' (10.18 mmol TE $\left.100 \mathrm{~g}^{-1}\right)$ and 'Imanta' (9.32 mmol TE $\left.100 \mathrm{~g}^{-1}\right)$.

Measured data gives reason to suggest that storage under fluorescent lighting generally reduces potato DPPH scavenging activity and longer storage might give more reduction (Xu et al., 2014). Experiments on strawberries showed that blue light increased 1,1-diphenyl-2picrylhydrazy (DPPH) radical-scavenging activity as well as ascorbic acid, total sugar content, titratable acidity content (Xu et al., 2014).

ABTS scavenging activity. The highest initial 2,2'-azinobis (3-ethylbenzothiazoline-6-sulphonic acid) (ABTS) scavenging activity (before treatment with light) was found in 'Blue Cong', i.e., $35.01 \mathrm{mmol} \mathrm{TE} 100 \mathrm{~g}^{-1}$ while 'Imanta' presented the lowest activity of $16.91 \mathrm{mmol}$ TE $100 \mathrm{~g}^{-1}$ (Fig. 5). 'Magdalena' and 'Lenora' both has insignificant differences in initial ABTS scavenging activity of $22.92 \mathrm{mmol}$ TE $100 \mathrm{~g}^{-1}$ and $22.32 \mathrm{mmol} \mathrm{TE}$ $100 \mathrm{~g}^{-1}$ respectively. After treatment with light potatoes of variety 'Lenora' showed slight increase of ABTS scavenging activity on day 3 . Although day 7 came with ABTS scavenging activity increase compared to day 3 , i.e., 'Magdalena' (29.19 mmol TE $100 \mathrm{~g}^{-1}$ ), 'Imanta' (25.05 mmol TE $\left.100 \mathrm{~g} \mathrm{~g}^{-1}\right)$ except in case of 'Lenora' that presented insignificant changes presenting
$26.57 \mathrm{mmol}$ TE $100 \mathrm{~g}^{-1}$. 'Blue Congo' potato peels showed the highest initial ABTS scavenging activity $18.41 \mathrm{mmol}$ TE $100 \mathrm{~g}^{-1}$ while 'Lenora' and 'Imanta' had insignificant differences in initial ABTS scavenging activity and at same time the lowest activity 13.69 mmol TE $100 \mathrm{~g}^{-1}$ and $13.13 \mathrm{mmol}$ TE $100 \mathrm{~g}^{-1}$, respectively (Fig. 5). 'Magdalena' showed $16.16 \mathrm{mmol}$ TE $100 \mathrm{~g}^{-1}$ initial activity. After treatment with light variety 'Magdalena' showed a decrease and 'Lenora' insignificant decrease of ABTS scavenging activity on day 3, except 'Blue Congo' that presented an increase and 'Imanta' that presented insignificant increase. Day 7 came with significant ABTS scavenging activity increase in all cases compared to day 3, i.e., 'Magdalena' (25.83 mmol TE $100 \mathrm{~g}^{-1}$ ), 'Lenora' (25.99 mmol TE $100 \mathrm{~g} \mathrm{~g}^{-1}$ ) and 'Imanta' (21.83 mmol TE $\left.100 \mathrm{~g}^{-1}\right)$ except in case of 'Blue Congo'.

Current study shows that ABTS scavenging activity experiences significant increase during potatoes storage under fluorescent light in period from day 3 to 7 except in case of one variety where slight decrease was experienced. Data suggest that longer storage might lead to greater activity changes.

\section{Correlation analysis}

Studies suggest that there is a correlation between phenolics and antioxidant capacity, and higher phenolic level might present also a stronger antioxidant effect (Andre et al., 2007). While the current study shows negative correlation between total phenolic content (TPC) and DPPH scavenging activity (Fig. 6) and between ABTS scavenging activity and DPPH scavenging activity (Fig. 8), there is still a positive correlation between total phenolic content and ABTS scavenging activity (Fig. 7).

Correlation of TPC and DPPH. 'Blue Congo' (A) and 'Lenora' (C) presented a strong negative correlation while 'Magdalena' (B) and 'Imanta' (D) showed a moderate negative correlation. Data suggests that changes of one parameter will substantially trigger changes of the other one in opposite direction.

Correlation of TPC and ABTS. 'Magdalena' (B) and 'Imanta' (D) presented a moderate positive correlation (Fig. 7), 'Blue Congo' (A) showed a strong positive correlation while 'Lenora' (C) had a very strong positive correlation. Obtained information allows putting forward 
the assumption that changes of one value will substantially force changes of other one in same direction, i.e., increase of one value will promote to increase other value.

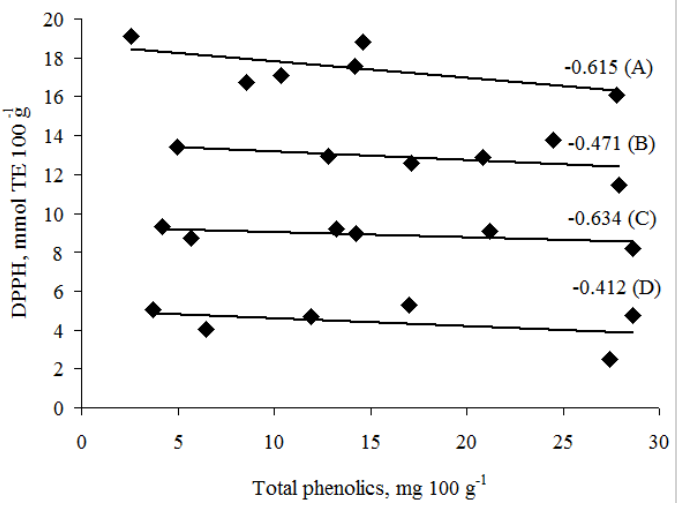

Figure 6. Correlation between total phenolic content and DPPH scavenging activity of potato

A - 'Blue Congo', B - 'Magdalena', C - 'Lenora', D- 'Imanta'

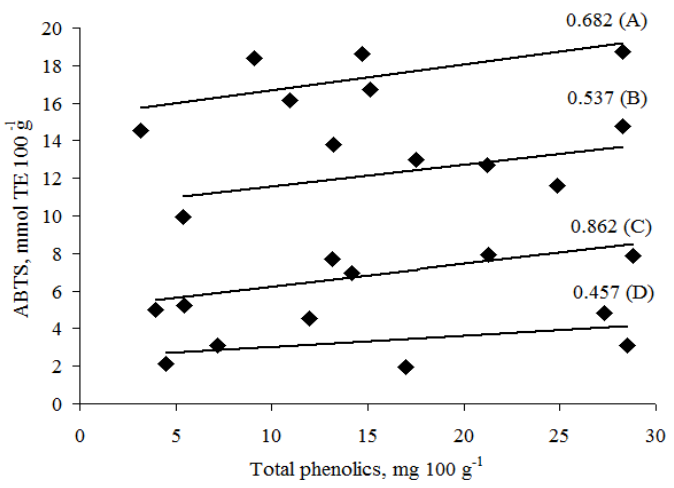

Figure 7. Correlation between total phenolic content and ABTS scavenging activity of potato

A - 'Blue Congo', B - 'Magdalena', C - 'Lenora', D- 'Imanta'

Correlation of DPPH and ABTS. 'Magdalena' (B) and 'Imanta' (D) presented a very strong negative correlation (Fig. 8), 'Blue Congo' (A) showed a strong negative correlation while 'Lenora' (C) had a weak negative correlation.

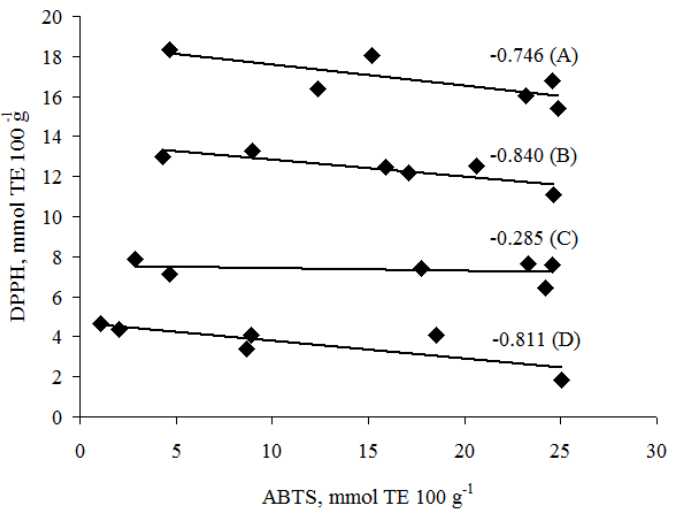

Figure 8. Correlation between DPPH scavenging activity and ABTS scavenging activity of potato A - 'Blue Congo', B - 'Magdalena', C - 'Lenora', D- 'Imanta'
From the obtained information we can see that parameters are negatively linked, i.e., one will substantially trigger changes of other in opposite direction, except in case of 'Lenora' that will experience only slight interaction of parameters.

\section{Conclusions}

During all storage period, potato firmness changed insignificantly, and in some cases a decrease in moisture was detected. Correlation between total phenolic content and DPPH scavenging activity, and between ABTS scavenging activity and DPPH scavenging activity was negative in all cases and ranged from a weak negative to a very strong negative correlation. Correlation between total phenolic content and ABTS scavenging activity was positive in all cases and ranged from a moderate positive to a very strong positive correlation. After exposure to fluorescent light phenolic compound level and antioxidant activity changed significantly, and those changes were dependent on potato variety.

\section{Acknowledgment}

Present research has been supported by the programme 'Strengthening Research Capacity in the Latvia University of Life Sciences and Technologies' project 'Effect of storage conditions and processing technology on dynamics of secondary metabolites in potatoes tubers' (Z16).

\section{References}

1. Al-Weshahy A., Rao V.A. (2009) Isolation and characterization of functional components from peel samples of six potatoes varieties growing in Ontario. Food Research International, Vol. 42(8), p. 1062-1066.

2. Andre C.M., Ghislain M., Bertin P., Oufir M., Herrera M.R., Hoffmann L., Hausman J.F., Larondelle Y., Evers D. (2007) Andean potato cultivars (Solanum tuberosum L.) as a source of antioxidant and mineral micronutrients. Journal of Agricultural and Food Chemistry, Vol. 55(2), p. 366-378.

3. Arezki O., Boxus P., Kevers C., Gaspar T. (2001) Changes in peroxidase activity, and level of phenolic compounds during light-induced plantlet regeneration from Eucalyptus camaldulensis Dehn. nodes in vitro. Plant Growth Regulation, Vol. 33(3), p. 215-219.

4. Ballester A.R., Lafuente M.T. (2017) LED blue lightinduced changes in phenolics and ethylene in citrus fruit: Implication in elicited resistance against Penicillium digitatum infection. Food Chemistry, Vol. 218, p. 575-583.

5. Berghe W.V. (2012) Epigenetic impact of dietary polyphenols in cancer chemoprevention: Lifelong remodeling of our epigenomes. Pharmacological Research, Vol. 65(6), p. 565-576.

6. Chalker-Scott L. (1999) Environmental significance of anthocyanins in plant stress responses. Photochemistry and Photobiology, Vol. 70(1), p. 1-9.

7. Chun O.K., Kim D.O., Smith N., Schroeder D., Han J.T., Lee C.Y. (2005) Daily consumption of phenolics and total antioxidant capacity from fruit and vegetables in the American diet. Journal of the Science of Food and Agriculture, Vol. 85(10), p. 1715-1724.

8. Espin J.C, Rivas C.S., Wichers H.J., Viguera, C.G. (2000) Anthocyanin based natural colorants: a new source of 
antiradical activity for foodstuff. Journal of Agricultural and Food Chemistry, Vol. 48(5), p. 1588-1592.

9. Ezekiel R., Singh N., Sharma S., Kaur A. (2013) Beneficial phytochemicals in potato - A review. Food Research International, Vol. 50(2), p. 487-496.

10. Grace M.H., Yousef G.G., Gustafson S.J., Truong V.D., Yencho G.C., Lila M.A. (2014) Phytochemical changes in phenolics, anthocyanins, ascorbic acid, and carotenoids associated with sweet potato storage and impacts on bioactive properties. Food Chemistry, Vol. 145, p. 717-772.

11. Huang D. (2018) Dietary antioxidants and health promotion. Antioxidants, Vol. 7(1), p. 1-3.

12. Im H.W., Suh B.S., Lee S.U., Kozukue N., OhnisiKameyama M., Levin C.E., Friedman M. (2008) Analysis of phenolic compounds by high-performance liquid chromatography and liquid chromatography/mass spectrometry in potato plant flowers, leaves, stems, and tubers and in home-processed potatoes. Journal of Agricultural and Food Chemistry, Vol. 56(9), p. 3341-3349.

13. Izquierdo A.M., Torres M.P.N., Jiménez G.S., Sosa F.C. (2011) Changes in biomass allocation and phenolic compounds accumulation due to the effect of light and nitrate supply in Cecropia peltata plants. Acta Physiologiae Plantarum, Vol. 33, p. 2135-2147.

14. Kampuse S., Tomsone L., Kruma Z., Sabovics M., Skrabule I. (2016) Effect of lovage phenolics to formation of acrylamide in French fries. Agronomy Research, Vol. 14(S2), p. 1315-1327.

15. Kazeem M.I., Akanji M.A., Hafizur R.M., Choudhary M.I. (2012) Antiglycation, antioxidant and toxicological potential of polyphenol extracts of alligator pepper, ginger and nutmeg from Nigeria. Asian Pacific Journal of Tropical Biomedicine, Vol. 2(9), p. 727-732.

16. Konate K., Hilou A., Mavoungou J.F., Lepengue A.N., Souza A., Barro N., Datte J.Y., M'Batchi B., Nacoulma O.G. (2012) Antimicrobial activity of polyphenol-rich fractions from Sida alba L. (Malvaceae) against cotrimoxazol-resistant bacteria strains. Annals of Clinical Microbiology and Antimicrobials, Vol. 11(1), p. $1-6$.

17. Leo L., Leone A., Longo C., Lombardi D.A., Raimo F., Zacheo, G. (2008) Antioxidant compounds and antioxidant activity in early potatoes. Journal of Agricultural and Food Chemistry, Vol. 56(11), p. 4154-4163.

18. Lewis C.E., Walker J.R.L., Lancaster J.E. (1999) Changes in anthocyanin, flavonoid and phenolic acid concentrations during development and storage of coloured potato (Solanum tuberosum L.) tubers. Journal of the Science of Food and Agriculture, Vol. 79(2), p. 311-316.

19. Manach C., Scalbert A., Morand C., Remesy C., Jimenez, L. (2004) Polyphenols: food sources and bioavailability. American Journal of Clinical Nutrition, Vol. 79(5), p. 727-747.

20. Mattila P., Hellstrom J. (2006) Phenolic acids in potatoes, vegetables, and some of their products. Journal of Food Composition and Analysis, Vol. 20 (3-4), p. 152-160.

21. Nara K., Miyoshi T., Honma T., Koga H. (2006) Antioxidative activity of bound form phenolics in potato peel. Bioscience, Biotechnology, and Biochemistry, Vol. 70(6), p. 1489-1491.
22. Nascimento L.B., Leal-Costa M.V., Coutinho M.A., Moreira N.S., Lage C.L., Barbi N.S., Costa S.S., Tavares E.S. (2013) Increased antioxidant activity and changes in phenolic profile of Kalanchoe pinnata (Lamarck) Persoon (Crassulaceae) specimens grown under supplemental blue light. Photochemistry and Photobiology, Vol. 89(2), p. 391-399.

23. Parr A.J., Bolwell G.P. (2000) Phenols in the plant and in man. The potential for possible nutritional enhancement of the diet by modifying the phenols content or profile. Journal of the Science of Food and Agriculture, Vol. 80(7), p. 985-1012.

24. Percival G.C., Baird L. (2000) Influence of storage upon light-induced chlorogenic acid accumulation in potato tubers (Solanum tuberosum L.). Journal of Agricultural and Food Chemistry, Vol. 48, p. 2476-2482.

25. Puchau B., Zulet M.A., Echavarri A.G., Hermsdorff H.H.M., Martínez J.A. (2010) Dietary total antioxidant capacity is negatively associated with some metabolic syndrome features in healthy young adults, Nutrition, Vol. 26(5), p. 534-541.

26. Sakihama Y., Mano J., Sano S., Asada K., Yamasaki H. (2000) Reduction of phenoxyl radicals mediated by monodehydroascorbate reductase. Biochemical and Biophysical Research Communications, Vol. 279, p. 949-954.

27. Scalbert A., Manach C., Morand C., Remesy C., Jimenez, L. (2005) Dietary polyphenols and the prevention of diseases. Critical Reviews in Food Science and Nutrition, Vol. 45(4), p. 287-306.

28. Singleton V.L., Orthofer R., Lamuela-Raventos R.M. (1999) Analysis of total phenols and other oxidation substrates and antioxidants by means of Folin-Ciocalteu reagent. Methods in Enzymology, Vol. 299, p. 152-178.

29. Sun H.N., Mu T.H., Xi L.S. (2017) Effect of pH, heat, and light treatments on the antioxidant activity of sweet potato leaf polyphenols. International Journal of Food Properties, Vol. 20(2), p. 318-332.

30. Terry L.A., Mena C., Williams A., Jenney N., Whitehead P. (2011) Fruit and vegetable resource maps: Mapping fruit and vegetable waste through the wholesale supply chain. Portland State University Business Faculty Publications and Presentations, Vol. 6, p. 1-92.

31. Velioglu Y.S, Mazza G., Gao L., Oomah B.D. (1998) Antioxidant activity and total phenolics in selected fruits, vegetables, and grain products. Journal of Agricultural and Food Chemistry, Vol. 46(10), p. 4113-4117.

32. Wang Q., Cao Y., Zhou L., Jiang C.Z., Feng Y., Wei S. (2015) Effects of postharvest curing treatment on flesh colour and phenolic metabolism in fresh-cut potato products. Food Chemistry, Vol. 169, p. 246-254.

33. Xu F., Shi L., Chen W., Cao S., Su X., Yang Z. (2014) Effect of blue light treatment on fruit quality, antioxidant enzymes and radical-scavenging activity in strawberry fruit. Scientia Horticulturae, Vol. 175, p. 181-186.

34. Zarins R., Kruma Z., Tomsone L., Kampuse S., Skrabule I., Konosonoka I. H. (2018) Comparison of phenolic compounds and antioxidant activity of fresh and freeze-dried potatoes, Agronomy Research, Vol. 16(2), p. $1546-1554$. 